Anggi Larasiska1, Wiwin Priyantari $\mathrm{HN}^{2}$

\title{
Menurunkan Tekanan Darah dengan Cara Mudah pada Lansia
}

1 Departemen Gerontik IImu Keperawatan, STIKES Yogyakara, JI Nitikan Baru No 69 Yogyakarta

${ }^{2}$ Lembaga Penelitian dan Pengabdian

Masyarakat, STIKES Yogyakarta, JI Nitikan Baru

No 69 Yogyakarta

Email :wpriyantari@yahoo.com

\section{Info Artikel:}

Masuk : 5 Februari 2017

Revisi : 20 Mei 2017

Diterima : : 4 Juni 2017

DOI Number : 10.18196/ijnp.1261

\begin{abstract}
ABSTRAK
Latar Belakang: hipertensi adalah suatu keadaan dimana tekanan darah sistolik lebih dari atau sama dengan $140 \mathrm{mmHg}$, dan tekanan darah diastolic lebih dari atau sama dengan $90 \mathrm{mmHg}$. World Health Organization (WHO) melaporkan terdapat 12,8\% kematian yang diakibatkan oleh hipertensi di seluruh dunia, dan sebanyak $40 \%$ orang dewasa telah menderita hipertensi. Tujuan Penelitian: untuk mengetahui pengaruh jalan kaki terhadap tekanan darah pada lansia dengan hipertensi di Balai Pelayanan Sosial Tresna Werdha (BPSTW) unit Budhi Luhur, Kasongan, Bantul, Yogyakarta. Metode Penelitian: jenis penelitian ini adalah kuantitatif dengan pendekatan time series design (desain rangkaian waktu). Populasi dalam penelitian ini sebanyak 88 responden dengan sampel sebanyak 12 responden yang diambil dengan menggunakan teknik purposive sampling. Hasil Penelitian: hasil uji Wilcoxon pada sampel didapatkan hasil untuk systole dengan nilai $z$ hitung $=-2,271$ dan $p$ value sebesar $0,023=\alpha<0,05$. Selain itu hasil untuk diastole dengan nilai $z$ hitung $=-2,530$ dan $p$ value sebesar $0,011=\alpha<0,05$ yang artinya ada pengaruh antara jalan kaki terhadap tekanan darah pada lansia hipertensi. Kesimpulan: jalan kaki mempengaruhi perubahan tekanan darah (turun) pada lansia dengan hipertensi.
\end{abstract}

Kata Kunci: hipertensi, jalan kaki, lansia

\section{ABSTRACT}

Background: hypertension is a State where the systolic blood pressure is greater than or equal to $140 \mathrm{mmHg}$, diastolic blood pressure and greater than or equal to $90 \mathrm{mmHg}$. The world health organization (WHO) report there is $12.8 \%$ of deaths caused by hypertension worldwide, and as much as $40 \%$ of adults had suffered from hypertension. Purpose: to know how 


\section{NURSING PRACTICES}

the walk against the blood pressure in the elderly with hypertension in the House social services Tresna Werdha (BPSTW) unit Budhi Sublime, Kasongan, Bantul, Yogyakarta. Method: the type of this research is quantitative approach to time series design (circuit design time). The population in this research as much as 88 respondents with samples as many as 12 respondents taken using purposive sampling technique. Results: Wilcoxon test results on samples obtained results for the $z$ value of systole count $=-2.271$ and $p$ value $=0.023 \alpha<0.05$. In addition the results to calculate the $z$ value of diastole $=-2.530$ and $p$ value $=0.011 \alpha<0.05$ meaning there influence between walk against blood pressure in elderly hypertension. Conclusion: walking affects blood pressure changes (down) on the elderly with hypertension.

Keywords: hypertension, walking, elderly

\section{PENDAHULUAN}

World Health Organization (WHO) melaporkan bahwa hipertensi atau tekanan darah tinggi menjadi penyebab kematian 12,8\% dari total penyebab kematian di seluruh dunia. Pada tahun 2008, jumlah orang dewasa (diatas 25 tahun) yang menderita hipertensi sebanyak $40 \%$, atau I dari 3 orang dewasa menderita hipertensi. Hipertensi menjadi isu kesehatan dunia karena kontribusinya yang tinggi pada penyakit seperti penyakit jantung, stroke, dan gagal ginjal. Di Indonesia, data ini masih bersifat sementara namun secara umum terkesan naiknya jumlah kasus hipertensi, sedangkan di daerah tersedia sedikit tenaga kuratif spesialis.

Salah satu tolak ukur kemajuan suatu bangsa seringkali dilihat dari harapan hidup penduduknya. Demikian juga Indonesia sebagai negara berkembang. Pada tahun 2020, jumlah lansia di Indonesia diproyeksikan sebesar I I,34\% (BPS, 1992). Semakin meningkatnya harapan hidup penduduk Indonesia, maka dapat diperkirakan bahwa insidensi penyakit degeneratif akan meningkat pula. Salah satu penyakit degeneratif yang mempunyai tingkat morbiditas dan mortalitas yang tinggi adalah hipertensi. Hipertensi pada usia lanjut menjadi lebih penting lagi, mengingat bahwa patogenesis, perjalanan penyakit, dan penatalaksanaanya tidak seluruhnya sama dengan hipertensi pada usia dewasa muda (R. Boedi et al, 2009).
Hipertensi merupakan penyebab kematian dan kesakitan yang tinggi. Darah tinggi sering diberi gelar the silent killer karena merupakan pembunuh tersembunyi yang menyebabkan kematian yang tanda-tanda awalnya tidak diketahui atau tanpa gejala sama sekali. Hipertensi bisa menyebabkan berbagai komplikasi terhadap penyakit lain, seperti penyakit jantung, stroke, dan ginjal (R. Boedi et al, 2009). Hipertensi atau lazim disebut penyakit tekanan darah tinggi merupakan salah satu penyakit yang sangat ditakuti oleh banyak orang di dunia ini. Ketakutan banyak orang terhadap penyakit ini bukan hanya disebabkan oleh akibat yang ditimbulkannya (bagi si penderita), akan tetapi sifat dan kemunculannya yang tiba-tiba dan sulit diduga (Rusdi et al, 2009).

Hasil survey yang dilakukan World Health Organization (WHO) tahun 2013 memperoleh hasil bahwa pada tahun 2012 jumlah kasus hipertensi di dunia adalah 839 juta kasus. diperkirakan akan semakin meningkat pada tahun 2025 dengan jumlah I, 15 milyar kasus atau sekitar 29\% dari total penduduk dunia. Prevalensi hipertensi di Indonesia sebesar $26,5 \%$ pada tahun 2013 , tetapi yang terdiagnosis oleh tenaga kesehatan dan/atau riwayat minum obat hanya sebesar 9,5\% (Kemenkes RI, 20I3), yang artinya bahwa 90,5\% masyarakat yang menderita hipertensi belum menyadari bahwa mereka menderita hipertensi. Hal ini menandakan bahwa tingkat kepedulian dan pengetahuan masyarakat yang menderita hipertensi masih sangat rendah tentang hipertensi, hal itulah yang membuat sebagian besar masyarakat yang menderita hipertensi belum terdiagnosis dan terjangkau oleh pelayanan kesehatan.

Pengaruh berolah raga khususnya jalan kaki terhadap penurunan tekanan darah dapat mencegah dan mengurangi komplikasi kardiovaskuler, hal ini disampaikan oleh organisasi The Amirican Heart Association, the Amirican College of Sports Medicine, the Surgeon General of the Unit-cardiorespied States telah mengelurkan pernyataan yang mendukung peran aktivitas fisik atau olah raga sebagai pengobatan non farmakologis pada hipertensi.

Telah banyak penelitian sebelumhya yang mendukung pernyataan bahwa aktivitas fisik berpengaruh terhadap tekanan darah pada hipertensi. Seperti, penelitian JE Martin dkk yang mengatakan bahwa latihan aerobic ringan dapat mengurangi tekanan darah sebesar 3,2 $\mathrm{mmHg}$ tekanan diastolic dan 
5,7 $\mathrm{mmHg}$ tekanan sistolik pada penderita hipertensi tanpa pengobatan. Penelitian serupa juga dilakukan oleh Fernando Dimeo dkk di brasil tahun 2012 yang mengatakan bahwa yang mengatakan bahwa olah raga secara teratur dapat menurunkan tekanan darah sistolik sebesar $6 \mathrm{mmHg}$ dan Diastolik sebesar $3 \mathrm{mmHg}$ pada penderita hipertensi yang resisten. Kelley dkk pada tahun 2000 mengatakan bahwa latihan resistensi progresif bermanfaat untuk mengurangi tekanan darah sistolik dan diastolic sebesar 2\% dan $4 \%$. Sedangkan menurut Augustine J. Sohn dkk di Afrika didapatkan penurunan tekanan darah sistolik sebesar $9,0 \%$ dan diastolic sebesar 7,42\% pada pasien hipertensi yang mendapatkan yang mendapatkanintervensi berjalan kaki selama 30 menit setiap harinya, dan proporsi pada kelompok yang tidak melakukan berjalan kaki sebesar 0,5 penelitian lain dilakukan oleh Mughal dkk pada tahun 2000 menyatakan bahwa latihan aerobik berupa berjalan kaki cepat selama 30 menit 3 sampai 5 kali perminggu pada penderita hipertensi primer dapat mengurangi tekanan darah sistolik dan diastolik istirahat sebesar 1,4 mmHg. Menurut The sevent Report of The Join National Committe on Prevetion, Detevtion, Evaluation, and Tratment of Hight Blood Pressure (JNC 7) kunci dari pemngobatan hipertensi adalah modifikasi gaya hidup, salah satunya denan cara berjalan kaki santai selama minimal 30 menit sehari dan dilakukan beberapa kali perminggu. Berjalan kaki merupakan olah raga yang bersifat ringan, sederhana, murah dan mampu dilaksankan oleh semua pasien hipertensi.

Beberapa penelitian lainya meyebutkan bahwa olah raga secara teratur dapat menurunkan rata-rata tekanan darah sebesar 5-7 mmHg dengan segera. Olahraga lebih mudah dikembangkan dan dimodifikasi sebagai gaya hidup dalam menurunkan prevalensi hipertensi karena mudah dilakukan, murah, dan sedikit efek samping apabila dilakukan. Olah raga dapat berperan sebagai tindakan preventif dan rehabilitative (Sidang, 2006). Jalan kaki dapat memberikan manfaat bagi kesehatan kita, terutama pada jantung, otot, persendian, tulang, metabolisme, bobot badan, dan juga pikiran. Berolahraga dengan jalan kaki dan dilakukan dengan teratur bisa menguatkan jantung, serta dapat meningkatkan efisiensi kerjanya memompa darah (Isnawati et al, 2009). Berdasarkan hasil studi pendahuluan yang dilakukan di salah satu Panti Whreda di Yogyakarta, 20 lansia yang menderita hipertensi, dan selalu mengikuti program olahraga rutin, namun tidak menunjukan adanya penurunan tekanan darah yang cukup berarti. Berdasarkan hal tersebut, sehingga penulis memandang perlu untuk dilakukan penelitian tentang "Pengaruh jalan kaki terhadap tekanan darah pada lansia"

\section{METODE DAN CARA PEMILIHAN SAMPEL}

Populasi dalam penelitian ini adalah lansia penghuni Balai Pelayanan Sosial Trena Werha Budi Luhur Kasongan Bantul Yogyakarta yang berjumlah 88 lansia. Penentuan sampel dengan menggunakan Purpsive Sampling.

Metode Penelitian ini menggunakan desain penelitian eksperimen semu (quasi eksperiment) dengan pendekatan kuantitatif dan menggunakan rancangan time series design (desain rangkaian waktu) dilakukan pre testt dan posttest sebanyak dua kali perlakuan. Tujuan dari dilakukan pre testt dan posttest secara berulang-ulang agar validitas menjadi tinggi, selain itu untuk mengurangi pengaruh dari variabel luar. Selain itu, desain ini tidak ada kelompok kontrol (pembanding) (Machfoedz, 20|4).

\begin{tabular}{|l|l|l|}
\hline Pre test & Perlakuan & Post test \\
\hline PI P2 P3 P4 & X & P5 P6 P7 P8 \\
\hline
\end{tabular}

Keterangan:

PI, P2, P3, P4 : Jumlah pre test

P5, P6, P7, P8 : Jumlah post test

$X$ : Perlakuan

Gambar 3.1: Rancangan peneltian Time Series Design (Machfoedz, 2014)

Penelitian ini sebelumnya belum pernah dialkukan di Balai Pelayanan Sosial Trena Werha Budi Luhur Kasongan Bantul Yogyakarta. Dalam tahap pelaksanaan penelitian, peneliti di bantu oleh 8 asisten peneliti. Sebelumnya responden di beri pengarahan dan di jelaskan posedur dan jalanya proses penelitian sekaligus dilakukan pengukuran tekanan darah sebelum melakukan jalan kaki (pre test). Kemudian responden melakukan jalan kaki di area panti selama 20 menit, kemudian di kumpulkan lagi untuk istirahat selama 10 menit, dan dilanjutkan dengan pengukuran tekanan darah kembali (post test). Hal ini dilakukan sebanyak dua kali dengan selang waktu selama dua hari. 


\section{NURSING PRACTICES}

HASIL

Analisa univariat

I) Karakteristik responden berdasarkan jenis kelamin

Tabel 1. Distribusi Frekuensi Karakteristik Lansia

Hipertensi Berdasarkan Jenis Kelamin di Balai

Pelayanan Sosial Tresna Wredha Unit Budhi Luhur

Kasongan Bantul Yogyakarta

\begin{tabular}{llll}
\hline No & Jenis Kelamin & Frekuesi & Prosentase \\
\hline I & Laki-laki & 3 & $25 \%$ \\
\hline 2 & Perempun & 9 & $75 \%$ \\
\hline & Total & 12 & $100 \%$ \\
\hline
\end{tabular}

Berdasarkan tabel I dapat diketahui bahwa jumlah lansia yang berjenis kelamin laki-laki sebanyak 3 orang (25\%), sedangkan yang berjenis kelamin perempuan sebanyak 9 orang (75\%)

\section{2) Karakteristik responden berdasarkan usia}

Tabel 2. Distribusi Frekuensi Karakteristik Lansia Hipertensi berdasarkan usia di Balai Pelayanan Sosial Tresna Wredha Unit Budhi Luhur Kasongan Bantul yogyakarta

\begin{tabular}{lccl}
\hline No & Usia & Frekuesi & Prosentase \\
\hline 1 & $60-69$ Tahun & 3 & $25 \%$ \\
\hline 2 & $70-79$ Tahun & 4 & $33,3 \%$ \\
\hline 3 & 80-89 Tahun & 5 & $41,7 \%$ \\
\hline & Total & 12 & $100 \%$ \\
\hline
\end{tabular}

\section{Analisa bivariat}

Distribusi frekuensi perubahan tekanan darah pada lansia hipertensi sebelum (pre test) dan sesudah (post test) melakukan olahraga jalan kaki adalah sebagai berikut:

I) Hasil perubahan tekanan darah sebelum dan sesudah melakukan kegiatan olahraga jalan kaki
Tabel 5. Tekanan Darah Sebelum dan Sesudah Olahraga Jalan Kaki pada Lansia Hipertensi di Balai Pelayanan Sosial Tresna Wredha Unit Budhi Luhur, Kasongan, Bantul, Yogyakarta

\begin{tabular}{llllllll}
\hline Samp & \multicolumn{2}{l}{ Perlakuan ke I } & \multicolumn{2}{l}{ Perlakuan ke II } & Rata-rata & Ket \\
\hline el & Pre test & $\begin{array}{l}\text { Post } \\
\text { test }\end{array}$ & Pre test & $\begin{array}{l}\text { Post } \\
\text { test }\end{array}$ & Pre test & $\begin{array}{l}\text { Post } \\
\text { test }\end{array}$ & \\
\hline I & $140 / 90$ & $160 / 90$ & $160 / 100$ & $120 / 80$ & $150 / 95$ & $140 / 85$ & Turun \\
\hline $\mathbf{2}$ & $140 / 80$ & $150 / 90$ & $130 / 90$ & $140 / 90$ & $135 / 85$ & $145 / 90$ & Naik \\
\hline $\mathbf{3}$ & $160 / 100$ & $140 / 80$ & $150 / 90$ & $140 / 90$ & $155 / 95$ & $140 / 85$ & Turun \\
\hline $\mathbf{4}$ & $170 / 110$ & $170 / 110$ & $150 / 100$ & $160 / 100$ & $160 / 115$ & $165 / 105$ & Naik \\
\hline $\mathbf{5}$ & $120 / 80$ & $120 / 80$ & $140 / 90$ & $130 / 90$ & $130 / 85$ & $125 / 85$ & Turun \\
\hline $\mathbf{6}$ & $130 / 90$ & $140 / 90$ & $100 / 70$ & $90 / 60$ & $115 / 80$ & $115 / 75$ & Turun \\
\hline $\mathbf{7}$ & $140 / 80$ & $150 / 80$ & $160 / 100$ & $150 / 90$ & $150 / 90$ & $150 / 85$ & Turun \\
\hline $\mathbf{8}$ & $170 / 100$ & $160 / 100$ & $150 / 90$ & $150 / 90$ & $160 / 95$ & $155 / 95$ & Turun \\
\hline $\mathbf{9}$ & $140 / 90$ & $150 / 90$ & $140 / 80$ & $140 / 80$ & $140 / 85$ & $145 / 85$ & Naik \\
\hline $\mathbf{1 0}$ & $130 / 90$ & $140 / 90$ & $130 / 90$ & $140 / 90$ & $130 / 90$ & $140 / 90$ & Naik \\
\hline $\mathbf{I 1}$ & $180 / 100$ & $160 / 100$ & $180 / 100$ & $160 / 100$ & $180 / 100$ & $160 / 100$ & Turun \\
\hline $\mathbf{1 2}$ & $130 / 80$ & $120 / 80$ & $130 / 80$ & $120 / 80$ & $130 / 80$ & $120 / 80$ & Turun \\
\hline & & & & & & &
\end{tabular}

Berdasarkan tabel 5 dapat diketahui bahwa dari 12 responden (lansia hipertensi) terdapat 8 responden (66,7\%) yang mengalami penurunan tekanan darah, tidak ada responden yang tekanan darahnya tetap, dan 4 responden (33,3\%) yang mengalami peningkatan tekanan darah. Hasil ini menunjukan bahwa mayoritas lansia hipertensi pada lansia di Balai Pelayanan Sosial Tresna Wredha (BPSTW) unit Budhi Luhur Kasongan Bantul Yogyakarta mengalami penurunan tekanan darah setelah melakukan olahraga jalan kaki.

2) Hasil perubahan tekanan darah dalam kategori turun

Tabel 6. Tekanan Darah dalam kategori turun pada lansia hipertensi di Balai Pelayanan Sosial Tresna Wredha Unit Budhi Luhur, Kasongan, Bantul,

Yogyakarta

\begin{tabular}{llllllll}
\hline Samp & \multicolumn{2}{l}{ Perlakuan ke I } & \multicolumn{2}{l}{ Perlakuan ke 2 } & \multicolumn{2}{l}{ Rata-rata } & Ket \\
\hline el & $\begin{array}{l}\text { Pre } \\
\text { test }\end{array}$ & $\begin{array}{l}\text { Post } \\
\text { test }\end{array}$ & $\begin{array}{l}\text { Pre } \\
\text { test }\end{array}$ & $\begin{array}{l}\text { Post } \\
\text { test }\end{array}$ & $\begin{array}{l}\text { Pre } \\
\text { test }\end{array}$ & $\begin{array}{l}\text { Post } \\
\text { test }\end{array}$ & \\
\hline I & $140 / 90$ & $160 / 90$ & $160 / 100$ & $120 / 80$ & $150 / 95$ & $140 / 85$ & Turun \\
\hline $\mathbf{3}$ & $160 / 100$ & $140 / 80$ & $150 / 90$ & $140 / 90$ & $155 / 95$ & $140 / 85$ & Turun \\
\hline $\mathbf{5}$ & $120 / 80$ & $120 / 80$ & $140 / 90$ & $130 / 90$ & $130 / 85$ & $125 / 85$ & Turun \\
\hline $\mathbf{6}$ & $130 / 90$ & $140 / 90$ & $100 / 70$ & $90 / 60$ & $115 / 80$ & $115 / 75$ & Turun \\
\hline $\mathbf{7}$ & $140 / 80$ & $150 / 80$ & $160 / 100$ & $150 / 90$ & $150 / 90$ & $150 / 85$ & Turun \\
\hline $\mathbf{8}$ & $170 / 100$ & $160 / 100$ & $150 / 90$ & $150 / 90$ & $160 / 95$ & $155 / 95$ & Turun \\
\hline $\mathbf{1 1}$ & $180 / 100$ & $160 / 100$ & $180 / 100$ & $160 / 100$ & $180 / 100$ & $160 / 100$ & Turun \\
\hline $\mathbf{1 2}$ & $130 / 80$ & $120 / 80$ & $130 / 80$ & $120 / 80$ & $130 / 80$ & $120 / 80$ & Turun \\
\hline
\end{tabular}


Berdasarkan tabel 6 diketahui bahwa terdapat 8 responden (lansia hipertensi) yang mengalami penurunan tekanan darah setelah melakukan olahraga jalan kaki, dimana terdapat 4 responden yeng mengalami penurunan tekanan darah Sistole, 2 responden yang mengalami penurunan tekanan darah Diastole, dan 2 responden yang mengalami penurunan tekanan darah Sistole dan Diastole.

3) Hasil perubahan tekanan darah dalam kategori naik

Tabel 7. Tekanan Darah dalam kategori naik pada lansia hipertensi di Balai Pelayanan Sosial Tresna Wredha Unit Budhi Luhur, Kasongan, Bantul, Yogyakarta

\begin{tabular}{llllllll}
\hline Samp & \multicolumn{2}{l}{ Perlakuan ke I } & \multicolumn{2}{l}{ Perlakuan ke 2 } & \multicolumn{2}{l}{ Rata-rata } & Ket \\
\hline & $\begin{array}{l}\text { Pre } \\
\text { test }\end{array}$ & $\begin{array}{l}\text { Post } \\
\text { test }\end{array}$ & $\begin{array}{l}\text { Pre } \\
\text { test }\end{array}$ & $\begin{array}{l}\text { Post } \\
\text { test }\end{array}$ & $\begin{array}{l}\text { Pre } \\
\text { test }\end{array}$ & $\begin{array}{l}\text { Post } \\
\text { test }\end{array}$ & \\
\hline $\mathbf{2}$ & $140 / 80$ & $150 / 90$ & $130 / 90$ & $140 / 90$ & $135 / 85$ & $145 / 90$ & Naik \\
\hline 4 & $170 / 110$ & $170 / 110$ & $150 / 100$ & $160 / 100$ & $160 / 115$ & $165 / 115$ & Naik \\
\hline 9 & $140 / 90$ & $150 / 90$ & $140 / 80$ & $140 / 80$ & $140 / 85$ & $145 / 85$ & Naik \\
\hline 10 & $130 / 90$ & $140 / 90$ & $130 / 90$ & $140 / 90$ & $130 / 90$ & $140 / 90$ & Naik \\
\hline
\end{tabular}

Berdasarkan tabel 7 diketahui bahwa terdapat 4 responden (lansia hipertensi) yang mengalami peningkatan tekanan darah setelah melakukan olahraga jalan kaki, dimana 3 responden mengalami peningkatan tekanan darah Diastole, dan I responden yang mengalami peningkatan tekanan darah Sistole dan Diastole.

Tabel 8. Hasil analisa Wilcoxon Pengaruh jalan kaki terhadap Tekanan Darah pada lansia dengan hipertensi di Balai Pelayanan Sosial Tresna Wredha Unit Budhi Luhur, Kasongan, Bantul, Yogyakarta

\begin{tabular}{llll}
\hline Tekanan & Z Hitung & P Value & Hasil \\
\hline Darah & & & \\
\hline Sistole & $-2,271$ & 0,023 & Beda Nyata \\
\hline Diastole & $-2,530$ & 0,011 & Beda Nyata \\
\hline
\end{tabular}

Berdasarkan hasil analisa uji Wilcoxon diketahui bahwa untuk Sistole nilai $Z$ hitung $=-2,27$ I dengan $p$ value $0,023=$ $\alpha<0,05$ yang berarti terjadi perubahan tekanan darah Sistole (turun) setelah melakukan olahraga jalan kaki. Sedangkan untuk Diastolenilai Zhitung $=-2,530$ dengan $p$ value $0.0 \mathrm{I}$ I $=\alpha<0,05$ yang berarti terjadi perubahan tekanan darah Diastole (turun) setelah melakukan olahraga jalan kaki.

Hasil ini menunjukan bahwa Ho ditolak, sehingga $\mathrm{Ha}$ diterima yang berarti bahwa hipotesis yang menyatakan bahwa ada pengaruh jalan kaki terhadap penurunan tekanan darah pada lansia hipertensi terbukti kebenarannya.

\section{PEMBAHASAN}

I) Tekanan Darah Lansia Hipertensi sebelum olahraga jalan kaki

Hasil analisa univariat tekanan darah lansia hipertensi sebelum melakukan olahraga jalan kaki yaitu |।5/80 $\mathrm{mmHg}$ sampai 165/l05 mmHg, dan lansia terbanyak yang mempunyai tekanan darah 140/85 mmHg sebanyak 2 lansia (16,7\%). Berdasarkan data tersebut, tekanan darah lansia terlihat bervariasi, ada yang rendah dan ada yang tinggi. Selain itu, berdasarkan tabel 4. I menunjukan bahwa terdapat 3 lansia yang berjenis kelamin laki-laki (25\%) dan 9 lansia yang berjenis kelamin perempuan (75\%). Hal ini sejalan dengan pendapat Depkes RI (2006), jenis kelamin sangat erat kaitannya terhadap terjadinya hipertensi dimana pada masa muda dan paruh baya lebih tinggi penyakit hipertensi pada laki-laki dan pada wanita lebih tinggi setelah berusia 55 tahun keatas dimana seorang wanita telah memasuki masa menopause. Prevalensi terjadinya hipertensi pada pria sama dengan wanita, namun wanita terlindung dari penyakit kardiovaskuler sebelum menopause. Wanita yang belum menopause dilindungi oleh hormon estrogen yang berperan dalam meningkatkan kadar High Density Lipoprotein (HDL).

Menurut Waren, et al. (2009) kadar kolesterol HDL yang tinggi merupakan faktor pelindung dalam mencegah terjadinya proses aterosklerosis. Efek perlindungan estrogen dianggap sebagai penjalasan adanya imunitas pada wanita setelah memasuki usia menopause. Pada premenopause wanita mulai kehilangan sedikit demi sedikit hormon estrogen yang selama ini melindungi pembuluh darah dari kerusakan. Proses ini berlanjut dimana hormon estrogen tersebut berubah kuantitasnya sesuai dengan umur wanita secara alami, yang pada umunya mulai terjadi pada usia 45-55 tahun.

Faktor usia juga sangat berpengaruh terhadap hipertansi, seperti yang ditunjukan dalam tabel 4.2 bahwa mayoritas lansia yang tinggal di BPSTW unit Budhi Luhur Kasongan Bantul Yogyakarta berusia 80-89 tahun (4I,7\%). Hal ini sejalan dengan pendapat Sesuai dengan pendapat Elshanti (2009) yang mengatakan bahwa dengan bertambahnya umur 


\section{NURSING PRACTICES}

seseorang maka semakin tinggi pula resiko akan terjadinya hipertensi. Insiden hipertensi menigkat seiring dengan bertambahnya umur dimana seseorang yang berumur diatas 60 tahun 50-60\% mempunyai takanan darah lebih dari atau sama dengan $140 / 90 \mathrm{mmHg}$. Hal ini merupakan pengaruh degeneratif yang terjadi pada orang yang bertambah usianya.

2) Tekanan Darah Lansia Hipertensi sesudah olahraga jalan kaki

Setelah dilakukan kegiatan intervensi (olahraga jalan kaki selama 10 menit) diperoleh data bahwa tekanan darah pada lansia hipertensiberkisar antara I | 5/75 sampaidengan I65/I 05 $\mathrm{mmHg}$, dan tekanan darah dengan frekuensi terbanyak adalah 140/85 mmHg (16,7\%). Dari hasil intervensi pada penelitian ini, perubahan tekanan darah pada lansia hipertensi setelah jalan kaki sangat terlihat perbedaannya (tabel 4.5). Dari hasil analisa bivariat, terlihat bahwa perubahan tekanan darah pada lansia hipertensi sebelum dan sesudah olahraga jalan kaki yaitu yang mengalami penurunan tekanan darah sebanyak 8 lansia (66,7\%) dan yang mengalami peningkatan tekanan darah sebanyak 4 lansia (33,3\%).

Dari data diatas menunjukan bahwa masih terdapat peningkatan tekanan darah setelah dilakukan intervensi (olahraga jalan kaki). Hal tersebut bisa saja diakibatkan oleh adanya kebiasaan hidup lansia seperti kebiasaan minum kopi maupun merokok dimana menurut penelitian yang dilakukan oleh Pratiwi (20 I I), bahwa frekuensi minum kopi berpengaruh positif dan signifikan terhadap kejadian hipertensi, karena kopi mengandung kafein dimana kafein akan mempengaruhi tekanan darah dengan cara meningkatkan kadar hormon katekolamin yang menstimulasi pusat vasomotor dan menstimulasi langsung miokard yang akan meningkatkan tekanan darah.

Adapun hubungan merokok dengan hipertensi adalah zat nikotin yang akan menyebabkan peningkatan tekanan darah. Nikotin mengganggu sistem saraf simpatis dengan akibat meningkatnya kebutuhan oksigen miokard. Selain menyebabkan ketagihan merokok, efek nikotin juga menyebabkan perangsangan terhadap hormon epinefrin (adrenalin) yang bersifat memacu peningkatan denyut jantung, sehingga menyebabkan gangguan irama jantung.

Menurut Riza (2008), mengemukakan bahwa olahraga jalan kaki yang dilakukan secara teratur dapat menjaga kestabilan tekanan darah karena peredaran darah akan menjadi lancar. Seseorang yang berolahraga secara teratur terbukti dapat menurunkan tekanan darah ke tingkat normal sebesar 50\% dibandingkan dengan orang yang jarang melakukan aktivitas tersebut.

3) Pengaruh Jalan Kaki terhadap Tekanan Darah pada Lansia Hipertensi

Berdasarkan tabel 8 hasil uji wilcoxon pada kelompok intervensi menunjukan bahwa nilai $Z$ hitung untuk Sistole sebesar -2,27I dengan pvalue 0,023 $\alpha<0,05$ dan untuk diastole nilai $Z$ hitung sebesar $-2,530$ dengan $p$ value 0,011 . Hasil ini menunjukan bahwa Ha diterima yang berarti hipotesis yang menyatakan ada pengaruh jalan kaki terhadap penurunan tekanan darah pada lansia hipertensi terbukti kebenarannya.

Hasil penelitian ini sesuai dengan penelitian Syatria (2006), yang menyatakan bahwa olahraga yang terprogram berpengaruh terhadap penurunan tekanan darah. Penelitian tersebut menjelaskan bahwa latihan fisik akan memberikan pengaruh yang baik terhadap berbagai macam sistem yang bekerja dalam tubuh, salah satunya adalah sistem kardiovaskuler, dimana dengan latihan fisik yang benar dan teratur akan terjadi efisiensi kerja jantung. Efisiensi kerja jantung ataupun kemampuan jantung akan meningkat sesuai dengan perubahan-perubahan yang terjadi.

Penurunan tekanan darah juga dapat terjadi akibat aktivitas memompa jantung berkurang. Otot jantung pada orang yang rutin berolahraga sangat kuat, maka otot jantung pada individu tersebut berkontraksi lebih sedikit daripada otot jantung individu yang jarang berolahraga untuk memompakan volume darah yang sama. Karena olahraga dapat menyebabkan penurunan denyut jantung maka olahraga akan menurunkan cardiag output, yang pada akhirnya menyebabkan penurunan tekanan darah. Peningkatan efisiensi kerja jantung dicerminkan dengan penurunan tekanan Sistole, sedangkan penurunan tahanan perifer dicerminkan dengan penurunan tekanan Diastole. Hasil penelitian tersebut menunjukan bahwa ada penurunan Sistole secara bermakna setelah dilakukan latihan olahraga terprogram (Syatria, 2006).

Penelitian lain yang hampir sama yaitu Sidang (2006) yang menyatakan bahwa olahraga berpengaruh terhadap penurunan tekanan darah pada penderita hipertensi. Penelitian tersebut menunjukan bahwa program intervensi 
yang diberikan adalah olahraga senam jantung sehat. Senam jantung sehat merupakan olahraga aerobik ringan dalam waktu yang relatif singkat. Hasil dari penelitian tersebut menunjukan bahwa dari hasil analisis multivariat, faktor yang berpengaruh terhadap penurunan tekanan darah Sistole dan Diastole pada penderita hipertensi adalah berolahraga dengan senam jantung sehat secara teratur dan terukur.

Jalan kaki sangat berpengaruh terhadap penurunan tekanan darah. Selain itu jalan kaki juga dapat mengurangi resiko terkena penyakit jantung. Otot jantung membutuhkan aliran darah lebih deras (dari pembuluh koroner yang memberikan suplai) agar bugar dan berfungsi normal memompakan darah tanpa henti. Untuk itu, otot jantung membutuhkan darah yang lebih keras dan lancar. Berjalan kaki tergopoh-gopoh memperderas aliran darah kedalam koroner jantung. Dengan demikian kecukupan oksigen otot jantung terpenuhi dan otot jantung terjaga untuk bisa tetap cukup berdegup. Bukan hanya itu, kelenturan pembuluh darah arteri tubuh yang terlatih menguncup dan mengambang akan terbantu oleh mengejangnya otot-otot tubuh yang berada disekitar dinding pembuluh darah sewaktu melakukan kegiatan berjalan kaki tergopoh-gopoh itu. Hasil akhirnya, tekanan darah cenderung menjadi lebih rendah, perlengketan antar sel darah yang bisa berakibat gumpalan bekuan darah dan penyumbat pembuluh darah akan berkurang (Kusuma, 2006).

Penulis menyadari bahwa penelitian ini masih banyak kelemahan yang menyebabkan hasil penelitian ini belum sempurna. Hal ini disebabkan oleh adanya keterbatasan dalam penelitian ini, yakni sebagai berikut:

I. Masih adanya variabel-variabel luar seperti pola hidup (kebiasaan merokok, minum kopi) yang ikut mempengaruhi variabel dependen, sehinggan peneliti mengabaikan variabel-variabel tersebut untuk menghilangkan bias atau confounding;

2. Masih adanya lansia yang tidak bersedia menjadi responden penelitian, sehingga penulis perlu melakukan pendekatan kepada lansia untuk dengan suka rela bersedia menjadi responden;

3. Terbatasnya jumlah sampel, sehingga hasil penelitian ini tidak dapat digunakan untuk menggeneralisasi pengaruh jalan kaki terhadapa tekanan darah dalam sampel yang lebih besar;
4. Adanya keterbatasan waktu, biaya, tenaga, pengalaman, dan pengetahuan dari penulis, sehingga hasil penelitian ini tidak maksimal;

5. Keterbatasan penggunaan bahasa antara peneliti dengan responden yang menyebabkan penelitian ini masih kurang sempurna.

\section{KESIMPULAN}

Penelitian ini bertujuan untuk mengetahui pengaruh jalan kaki terhadap tekanan darah menghasilkan kesimpulan sebagai berikut:

I) Tekanan darah pada lansia hipertensi sebelum melakukan kegiatan olahraga jalan kaki yaitu antara I I5/80 mmHg sampai dengan 165/l05 mmHg, dan frekuensi terbanyak yang mempunyai tekanan darah 140/85 $\mathrm{mmH}$ g sebanyak 2 lansia (16,7\%).

2) Tekanan darah pada lansia hipertensi sesudah melakukan kegiatan olahraga jalan kaki yaitu antara I I5/75 sampai dengan 165/l05 mmHg, dan frekuensi terbanyak yang mempunyai tekanan darah 140/85 mmHg sebanyak 2 lansia (16,7\%).

3) Jalan kaki mempunyai pengaruh yang signifikan terhadap penurunan tekanan darah pada lansia hipertensi.

\section{REFERENSI}

Adib,M. 2009. Cara Mudah Memahami dan Menghindari Hipertensi, Jantung dan. Stroke. Edisi ke-2. Yogyakarta : Dianloka Printika.

Augustina. J. 2008. Impact of Exersice (walking) on Blood Pressure Levels in Hypertension in African American Adults with Newly Diagnosed Hypertension.

American College of Sports Medicine. 2004. Jurnal. Diakses pada tanggal 15 Mei2016 dari https://www.acsm. org/docs/other-documents/50-years-of-progress-andservice.pdf?sfvrsn $=0$

Anggraini, D.A, dkk. (2009). Faktor-Faktor yang Berhubungan dengan KejadianHipertensi pada Pasien yang Berobat di Poliklinik Dewasa Puskesmas Bangkinang Periode Januari Sampai Juni 2008. Skripsi. Di akses padatanggal 15 mei 2016 dari http://yayanakhyar.files.wordpress. com/2009/02/files-of-drsmed-faktor-yangberhubungan-dengan-kejadian-hipertensi.pdf. 


\section{NURSING \\ PRACTICES}

Bare BG., Smeltzer SC. 2001. Buku Ajar Keperawatan Medikal Bedah. Jakarta: EGC.

Boedhi, Darmojo, R. 2011. Buku Ajar Geriatic (IlmuKesehatanLanjutUsia) edisi ke - 4.Jakarta :BalaiPenerbit FKUI

BPS, 1992. Jumlah Hipertensi di Indonesia. Jakerta: BPS Pusat.

Dalimartha, S. et al. 2008. Care Your Self Hipertensi. Jakarta: Penebar Plus +

Depkes RI. 2001. Pedoman Pengukuran dan Pemeriksaan. Jurnal. Depkes RI, Jakarta. 2006. Pedoman Pengukuran dan Pemeriksaan. Jurnal. Depkes RI, Jakarta.

Dinas Kesehatan Provinsi DIY. 2013. Profil Kesehatan DIY 2013. Yogyakarta : Dinas Kesehatan DIY 2013.

Dinkes DIY, 2013. Laporan Survailans Terpadu Penyakit (STP) Puskesmas di DIY pada tahun 2012,

Elsanti, Salma. 2009. Panduan Hidup Sehat Bebas Kolesterol, Stroke, Hipertensi \& Serangan Jantung. Yogyakarta : Araska.

Fernando Dimeo,

Handayani dan Riyadi, 2011. Pedoman Penelitian Karya Tulis Ilmiah Bidang Kesehatan. Yogyakarta : Samodra Ilmu Perss

Hans. Tandra. 2003. Merokok dan. Kesehatan. http://www. kompas.co.id/kesehatan/news/0306/30/105012.htm, 24 juni 2007

Hikmaharidha. 2011. Pengaruh Senam Tai Chi Terhadap Tekanan Darah Wanita Berusia 50 Tahun Keatas. Skripsi.

J E Martin, P M Dubbert. Controled Trial Aerobic Exersice of Hypertention, Dallas 1990.

Karyadi, E. 2002, Hidup Bersama Penyakit Hipertensi, Asam Urat dan Jantung. Koroner. Jakarta : Intisari Mediatama.

Kementrian Kesehatan RI. (2013). Riset Kesehatan Dasar 2013. Jakarta : Kementrian Kesehatan RI 2013.

Krummel, D.A. 2004. Medical Nutrition Therapy in Cardiovascular Disease. In:Mahan, L.K. $\mathcal{E}$ Escott-Stump, S., ed. Krause's Food, Nutrition, \& Diet.

Kumar, 2005. Kumar V, Abbas AK, Fausto N. Hypertensive Vascular Disease. In: Robn and Cotran Pathologic Basis of Disease 7th edition. Philadelpia : Elsevier https:// id.wikipedia.org/wiki

Kusuma, D. 2006. Olahraga Untuk Orang Sehat dan Penderita Penyakit Jantung. (Internet) http://www. afand.abatasa.com.(aAccessed 10 Juni 2015).

Machfoedz, Ircham. 2014. Me todologi Penelitian Kuantitatif. Yogyakarta: Fitramaya.

Marliani L, S Tantan. 2007. 100 Questions \& Answer Hipertensi. Jakarta: Elex Media Komputindo.

Marya, et al. 2008. Mengenal Usia Lanjut dan Perawatannya. Jakarta: Salemba.

Murwani, et al. 2010. Gerontik konsep dasar dan asuhan keperawatan home care dan komunitas. Yogyakarta : Penerbit Fitramaya.

National Institutes of Health. 2004. Prevention, Detection, Evaluation, andTreatment of High Blood Pressure (JNC 7).Jurnal. U.S. Department Of Health And Human Services Notoatmodjo, Soekidjo. 2012. Mtodologi Penelitian Kesehatan, Edisi Revisi. Jakarta : Rineka Cipta.

Larisa, et al. 2013. Hubungan Kebiasaan Berolahraga Jalan Kaki Dengan Kontrol Tekanan Darah Pada Pasien Hipertensi.

Rohaendi. 2008. Treatment Of High Blood Pressure. Jakarta :Gramedia Pustaka Utama.

Rusdi \&Nurlaela Isnawati. (2009). Awas! Anda bisa mati cepat akibat hipertensi \&diabetes. Yogyakarta : Power Books (IHDINA).

Saraswati, S. 2009. Diet Sehat Untuk Penyakit Asam Urat, Diabetes, Hipertensi, dan Stroke. Jogjakarta : A+Plus.

Syatria, A. 2006. Pengaruh Olahraga terprogram terhadap tekanan darah pada mahasiswa fakultas kedokteran universitas diponegoro. FK UNDIP. Semarang.

Sidang. 2006. "Pengaruh Olahraga Terhadap Penurunan Tekanan Darah pada Penderita Hipertensi di Klub Jantung Sehat Bhumi Phala Kabupaten Temanggung”. Skripsi.

Sugiyono, 2010. Metode Penelitian Kualitatif Kuantitatif \& RND. Bandung:Alfabeta.

Susalit dkk, 2001. Hipertensi Primer Dalam Buku Ajar Ilmu Penyakit Dalam, Edisi III, Jilid II. Jakarta: Balai Penerbit FKUI.

Sustrani, Lanny, dkk. 2006. Hipertensi. Jakarta : PT Gramedia Pustaka Utama. 
Sutanto. 2009. Awas 7 Penyakit Degeneratif, Paradigma Indonesia,Yogyakartahttps://id.wikipedia.org/wiki.

Thristyaningsih. 2009. Pengaruh Senam Bugar Lansia Terhadap Daya Tahan Jantung Paru, Status Gizi dan Tekanan Darah Lansia Hipertensi di Posyandu Kecamatan Pahandut. Kota Palangkaraya. Tesis. FK UGM. Yogyakarta.

Waren, et al. 2009. Faktor-Faktor Yang Berhubungan Dengan Kejadian Hipertensi Pada Pasien Yang Berobat Di Poliklinik Dewasa Puskesmas Bangkina Periode Januari Sampai Juni 2008. FK. UNRI. Riau

World Health Organisation (WHO). 2011. Global Adult Tobacco Survey:Indonesia Report 2011. Jurnal. Jakarta. 